J. Neurol. Neurosurg. Psychiat., 1955, 18, 72.

\title{
ALZHEIMER'S DISEASE WITH ACNE ROSACEA IN ONE OF IDENTICAL TWINS
}

BY

\section{ESTHER A. DAVIDSON and E. ELIZABETH ROBERTSON}

\section{From Bangour Mental Hospital and the Royal Edinburgh Hospital for Mental and Nervous Disorders}

\begin{abstract}
Although Alzheimer's disease has been known for some 50 years it is only in the last 20 that any considerable literature has grown up around its genetic aspects. At a Royal Society of Medicine discussion on presenile dementia in 1932, for instance, Critchley could express legitimate surprise when two of the speakers cited familial cases of Alzheimer's disease and could point out with accuracy that no such familial cases had previously been reported in the literature. In that same year, however, Schottky (1932) described the occurrence of Alzheimer's disease in a father and daughter, and from then onwards sporadic cases of parent-child incidence and/or sibling incidence have continued to be reported. The most recent is that described by Essen-Möller (1946) and concerns a father, son, and daughter all of whom developed Alzheimer's disease in their fourth decade. Slater (1950), referring to this particular case, goes so far as to say that it gives support to "the prevailing impression that this disease depends on a dominant gene ", a statement which indicates the degree of acceptance of a genetic basis by some present-day writers on the subject.

The approach to the genetic aspects of Alzheimer's disease is often widened to include senile dementia. This attitude emphasizes that dichotomy of opinion on the nature of Alzheimer's disease which was not only apparent at its initial formulation but persists to the present day. Alzheimer (1907) regarded the syndrome described by himself as an atypical form of senile dementia, but Kraepelin (1910), impressed by the earlier age of onset and by a collection of symptoms which differed in his opinion from that found in senile dementia, was disposed to consider it a disease sui generis, for which he proposed the title of Alzheimer's disease. Those observers whose interest has been directed predominantly to the clinical aspects of Alzheimer's disease have continued to endorse Kraepelin's conclusion, holding that the early onset, the characteristic personality changes, the severe degree of intellectual deterioration with
\end{abstract}

its profusion of focal symptoms of an aphasic and agnostic type, and the frequent coincidence of epileptiform seizures constitute a specific clinical entity distinct from senile dementia. Nevertheless, the underlying pathological changes are indistinguishable from those found in senile dementia. Consequently many authorities would deny the validity of any hypothesis which separates Alzheimer's disease from senile dementia. Newton (1948), in a study of the histopathological finding in 150 consecutive mental hospital necropsies, demon strated miliary plaques in 14 of the 59 cases in the age group 60-64 years, and in 37 of the 52 in the age group 65-96 years, and concluded therefrom that Alzheimer's disease, senile dementia, and normab senility are "examples of the same condition occurring? at different ages ". He considers that research intes" the aetiology of these conditions has failed to produce results because it has been sought in the environment and not in the cell itself : "the problem, therefore, becomes one of genetics ". The tacit acceptance of Newton's concept of the indivisibility of Alzheimer's disease and senile dementia is implicit in the work of Sjögren, Sjögren, and Lindgren (1952), who attempt the more specific task of establishing genetic uniformity between these two disease processes. Taking as their point of departure a group of 80 cases of presenile dementia admitted to various Swedish hospitals, they proceeded to investigate their families and forebears in considerable detail. The initial group was a somewhat heterogeneous collection consisting of 18 histopathologically verified cases of Alzheimer's disease ; 18 histopathologically verified cases of Pick's disease ; 29 cases with the generic title "Pick-Alzheimer syndrome" where cerebral atrophy had been verified by encephalography or post-mortem examination, but histopathological examination was lacking; and 15 cases of PickAlzheimer syndrome where the diagnosis was based on clinical findings alone.

Investigation of the families of these 80 patients 
revealed that in the family histories of 20 of them, 30 "secondary" cases were isolated. The diagnosis made in these " secondary" cases was that of senile dementia or Pick-Alzheimer syndrome. Sjögren and his colleagues consider these figures statistically significant. The inclusion in their material of cases of Pick's disease unfortunately confuses the issue. When attention is concentrated on the pedigrees of their 18 histopathologically verified cases of Alzheimer's disease we find that the first is the case of Essen-Möller (1946) referred to above and in only two others was there a history of senile dementia in one parent.

This recent preoccupation with genetic factors in Alzheimer's disease, whether or not extended to include senile dementia, makes it seem worth while to describe Alzheimer's disease in one of female identical twins. The other twin is still alive, aged 73 , and is pursuing a normal life four years after the death of her sister, in whom symptoms first made their appearance at the age of 50 .

\section{Case Report}

Mrs. Margaret O., aged 63, was admitted on March 5, 1943, to the Royal Edinburgh Hospital for Mental and Nervous Disorders, and died on October 12, 1949, being then 69 years of age.

The first deviations from normal occurred some 13 years before admission to hospital (in 1930, when the patient was aged 50), and took the form of gradually failing domestic efficiency associated with personality changes. Formerly meticulous about the weekly laundering, she now hung out articles inadequately washed. She became more irritable, less careful about her personal appearance, less interested in social outings. (The latter was first attributed to self-consciousness about an acne rosacea which made its appearance about this time.) She took a dislike to her twin sister, to whom she had been devoted. Over the ensuing 10 years there was a progressive but insidious deterioration of her mental faculties; she became slower in her performance of domestic duties and showed increasing memory defects. Three years before admission more florid mental symptoms of a delusional type appeared and ushered in a more accelerated decline. She accused her husband of consorting with other women, and on one occasion she locked the house against him, and on another attacked him with physical violence. Admitted for investigation to a general hospital, where her illness was diagnosed as cerebral arteriosclerosis, she accused the staff of immoral behaviour and attempted to escape through a balcony window. She had phases of nocturnal restlessness, when she would remove the black-out protection from the windows and disarrange the furniture. During the two years preceding her admission she was quite unable to attend to her household, and her memory defect was so extreme that she would turn on the gas and omit to light the jet. She became unable to carry on a conversation, having obvious difficulty in finding the necessary words, in forming sentences, and in retaining the gist of questions addressed to her. She could not write her name. She showed disorientation for time and place, misidentified persons in her environment (including her husband) and appeared to recognize only her two daughters. She took her food well and was not incontinent.

The patient was a healthy-looking middle-aged woman. A moderate degree of acne rosacea, characterized by erythema and acneiform papules and pustules, was present over the nose, cheeks, and left lower eyelid, but the conjunctiva was unaffected. Examination of the central nervous system revealed no focal neurological signs in the somatic sphere. Examination of other systems likewise showed no abnormality. A blood Wassermann reaction was negative.

When greeted, she responded by an immediate smile, and although obviously unable to achieve adequate verbal rapport, she indicated by gesture her eagerness to cooperate with the examiner. She showed a degree of psychomotor overactivity, constantly walking up and down the ward reiterating greetings to her fellow patients, and, during the interview, playing interminably with the cord of her dressing gown.

She proffered no spontaneous remarks but invariably responded to questions. Her replies, however, were usually incomplete and frequently inaccurate or irrelevant. She tended to grope for words, making one or two attempts before achieving accurate pronunciation. Her vocabulary was reduced to the simplest elements of speech, and her comprehension was so defective that she did not always understand questions couched in similarly simple terms. Asked her name, she replied, "Margaret (pause) eh, fancy now, that's funny, fancy I've forgotten. I've not been thinking. I was never like that. Just Margaret, isn't it ?" Asked her surname, she transposed components of her maiden and married names so that the resulting word sounded like an anagram of both. Asked her husband's name, she replied by giving his occupation, and on repetition of the question, perseverated by giving her own Christian name. Requests to demonstrate parts of her own body usually resulted in accurate responses. Shown simple objects she was able to evince some appreciation of their purpose : key, "putting in the door" ; matches, " for to light" ; letter, "I'll need my glasses". She was unable to read sentences in large print, but on occasion pointed to random words and named them correctly. She was unable to write to dictation, to copy or to sign her own name. She could not essay the simplest calculations. Memory was grossly impaired. Given a name, a vegetable, and a colour, she was unable to repeat them after an interval of one minute. She could not recite any of the universally known jingles and nursery rhymes. Questions relating to previously acquired knowledge rarely obtained an accurate response, e.g., Q. "What is the King's name?" A. "Isn't that funny, I should think (i.e., know) that" (with an air of bewilderment).

Her mood was euphoric : she smiled and laughed and was obviously unaware of her total situation. She seemed episodically surprised, however, by her inability to supply 


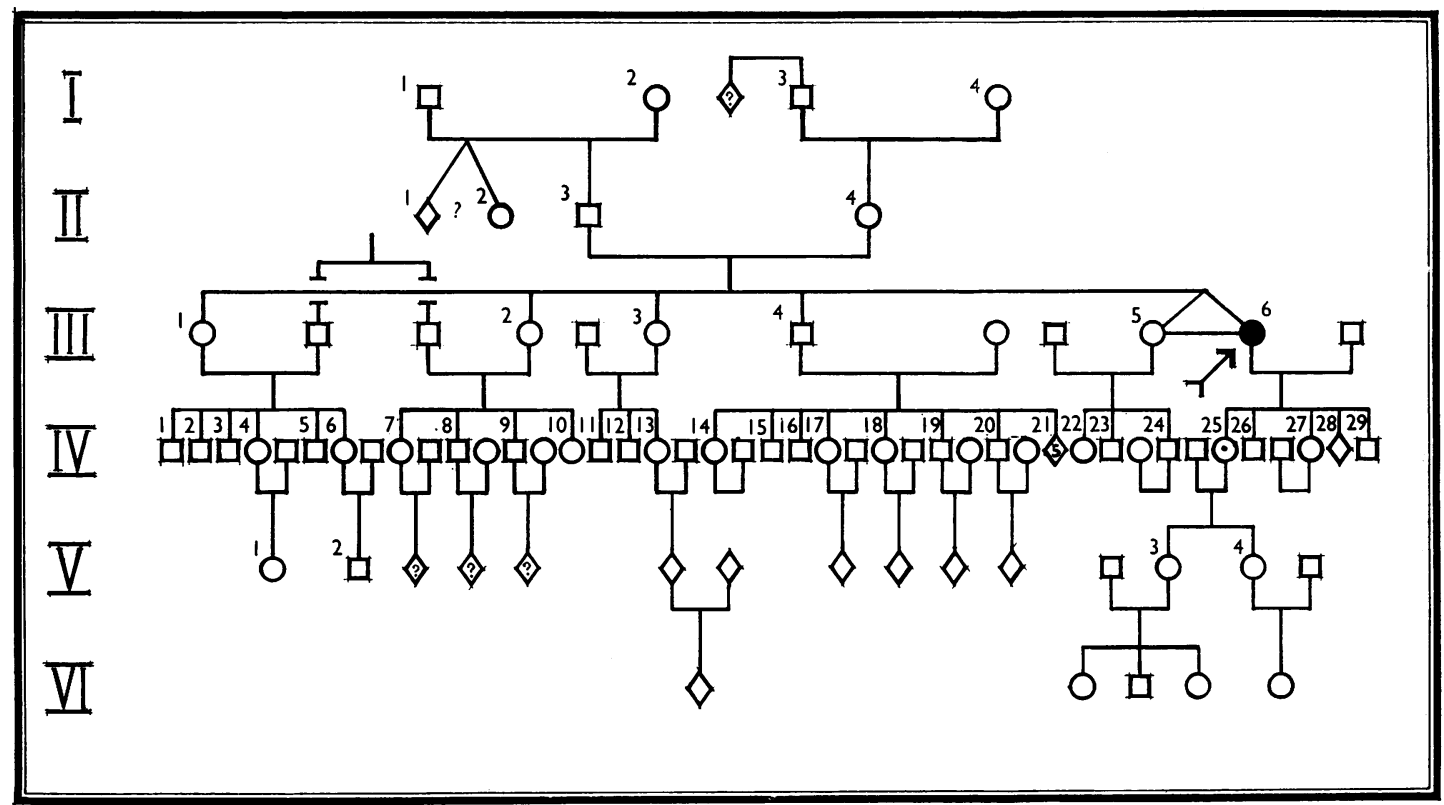

Fig. 1.-Pedigree of the twins.

I. 1 and 2 , nothing known ; 3 , died aged 45 years ; 4 , died at 80 years.

II. 1 and 2, twins, uncertain if identical. 1, stillbirth; 2, lived to old age ; 3, died at 62 years of silicosis ; 4, died at 62 years of galle stones.

III. 1 and 2 married brothers ; 1, died at 72 years of heart disease ; 2, died at 46 years of bronchitis ; 3, died at 30 years of inanition , 4 , died at 41 years of aortic disease and mitral incompetence; 5 , alive and well at 73 years, twin of 6 (propositus).

IV. 1-6 and 7-10, first cousins but genetically siblings; 22-24 and 25-29, first cousins but genetically half-siblings. 1, died at 18 years of septicaemia ; 2 , died at 49 years, cause not known; 3, died in infancy; 4, alive and well at 66 years; 5 , died at 50 years by accident; 6, 7, 8, and 9, alive and well all aged 50 years; 10, died at 14 years " faint at menarche" (sic); 11, 12, and 13, ? aliv and well ; 14, died at 49 years, cause not known; 15 and 16, died in infancy ; 17, 18,19, and 20, alive and well ; 21, 5 others, nothing known-o 22 , alive and well, acne of face, age 40 years; 23, died at 1 year of diphtheria ; 24, alive and well, ? 35 years; 25, died at 36 years, asthm; following anaphylactic serum reaction at age of 25 years, had attacks of muscular rigidity with loss of consciousness, no mental disorder $\vec{\sigma}$ 26 , died at 2 years of tuberculous enteritis; 27 , alive and well, ? 40 years ; 28 , miscarriage.

V. 1, alive and well, 33 years ; 2, alive and well aged 29 years ; 3, alive, 20 years, in poor health following quick succession of pregnancies ; 4, 21 years, alive and well.

the demanded information, and her most sustained utterances took the form of artless rationalizations of her incapacity ; for example, "I let my man do everything. I see now I should have done things myself. He said ' Do it yourself .' I said 'You do it-you write nicer.',

Removed from hospital by her relatives after four months' residence, she was returned within 12 months because of the impossibility of caring for her at home. It was noted then that, while she still smiled brightly when addressed, questions and commands elicited no positive action or intelligible speech. Within two years of her return, her increasing unsteadiness of posture made it necessary to confine her to bed. During the last three years of her life she lay immobile, her head assuming the "psychical pillow" attitude mentioned by Critchley (1933), her limbs showing a hypertonus on passive manipulation. She also showed curious jerky movements of the trunk and limbs, which occurred at irregular intervals throughout the day. The latter were quite different in nature from the infrequent generalized epileptic fits which were also a feature of the terminal period. During her last year of life she became emaciated, developed contractures, and also recurring excoriation of the skin over dependent areas. Yet even at this stage she still essayed an answering smile when spoken to. The acne rosacea, present on admission, persisted unchanged till her death.

Investigation of the patient's ancestry, both direct and collateral, revealed no evidence of mental or nervous disease in any one member. There was no history of consanguineous marriages. The patient and her twin were born at the end of the reproductive life of the mother, who had had five previous pregnancies (Fig. 1).

History of Patient and Her Twin.-Margaret, our patient, and Chrissie, her twin, were born in 1880, and so far as is known no complications attended their birth, which occurred when their mother was 45 years of age. The patient was the second born of the twins. Both were breast fed. Their early development was similar. Their school records were comparable and somewhat above average. On leaving school, both went to work in the same paper factory and remained there till their respective marriages. They lived at home till the death of their parents and then lived together in the same lodgings. This close association ended in their twenty-seventh year 
when Margaret married. Their paths diverged still further three years later when Chrissie left this country for her marriage in Australia. Margaret spent her entire life in her native town of Edinburgh. Chrissie lived for over 20 years in Australia, at first in Sydney and later in Brisbane. Following the death of her husband, she returned to Scotland with her two children in 1930. Met on her arrival by her twin, Chrissie was struck by something strange in Margaret's appearance and demeanour and always remembered her own first remark at that meeting, which was, "I hope $I$ don't look like that". (lt is significant that Chrissie was the first to notice the change in the patient's appearance and personality, although her husband had observed concomitantly the commencing failure in domestic efficiency.)

Each twin had two children who survived to adult life. Of Margaret's five pregnancies, the last two ended in miscarriages, and her second child died of tuberculosis in childhood. Chrissie had three full-term infants, the second of whom died in childhood of diphtheria.

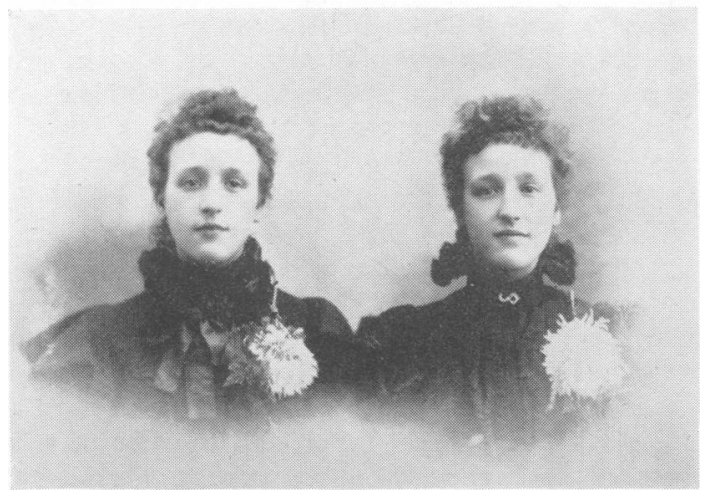

FiG. 2.-The twins as young women.

Margaret (the patient) was regarded as being less robust than her twin in childhood, having frequently recurring sore throats and quinsy. Chrissie, however, suffered from both scarlet fever and whooping-cough, which her twin escaped. Margaret suffered from influenza during the 1918-19 epidemic, and the illness was severe with delirium and high fever. Chrissie, then in Australia, suffered from pleurisy the following year. Margaret had an attack of whooping-cough at the comparatively late age of 30 .

All observers who knew them in youth were agreed that the twins resembled each other in personality traits as in appearance and mannerisms. Both were lively, high-spirited, and fond of playing practical jokes in which they impersonated each other, but conscientious at their work and regular in their church attendance. Minor temperamental differences existed. Margaret was more meticulous, more prone to worry and more sensitive than Chrissie. She was more easily moved to anger. She was less flexible, less adept at making friends, less adventurous in the world of business. Chrissie admitted frankly that her slightly greater social popularity arose from her " being more lazy and pleasant by nature".
Following the admission to hospital of the patient, Margaret, her twin, Chrissie, was examined by one of us (E. A. D.), who found that the twins showed all the similarities of physical configuration which are accepted as strong contributory evidence of uniovularity. Chrissie was so conscious of the close physical similarity existing between herself and her twin that she lived in constant dread of developing a similar illness, and since this feeling was exacerbated every time she saw her twin, she visited her in hospital at first infrequently and finally not at all. To this circumstance can be attributed the unfortunate

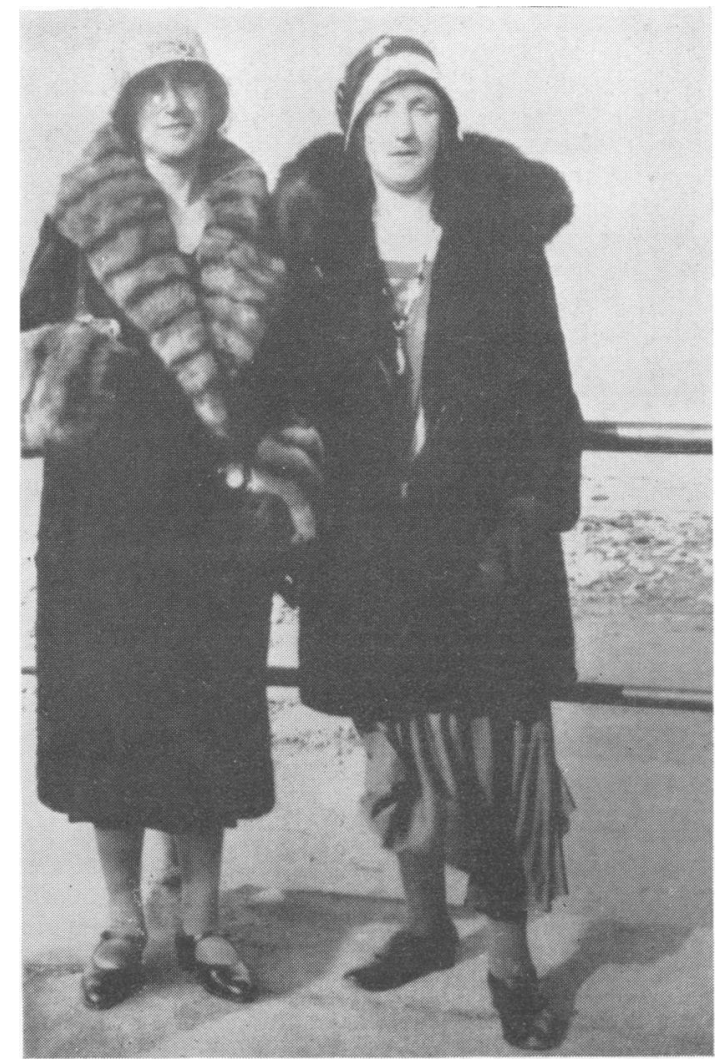

FIG. 3.-The twins after the onset of the patient's illness.

omission of finger-print and blood-group tests. All the available evidence, however, strongly confirmed uniovularity. The surpassing similarity of the twins was such that even members of their family circle were unable to distinguish the one from the other. The only person who could do so in childhood was their father, who, after keeping secret for many years his basis of identification, finally confessed that he was able to detect in Chrissie a slight droop of the left angle of the mouth not apparent in Margaret. Friends of one twin meeting the other in the street constantly greeted her as the twin of their acquaintance, and this misidentification was particularly marked on Chrissie's return from abroad, when she found 
herself hailed as Margaret by all the latter's friends. A physical peculiarity confirming uniovularity was that when the hair of both twins turned white at the same time, at the age of 40 , they each had a residual brown patch of hair in exactly the same position. Following Margaret's death, her daughter, when unexpectedly confronted by her aunt, was constrained to call out, "Oh, mother!"

A photograph of the twins taken in their youth reveals the striking similarity existing between them (Fig. 2). Another taken after the onset of Margaret's illness shows notable changes in her appearance, in the form of flattening of the facial muscles, a certain fixity of expression, and a sloppiness and lack of fashion in her dress (Fig. 3).

In an interview, following the patient's admission to hospital, her twin, Chrissie, gave a clear and concise account of the patient's early history and the various stages of her illness. Chrissie had no difficulty in word finding, in recalling recent and remote events, or in describing minutiae of temperamental similarities and differences existing between the patient and herself. Although willing to proffer information, she refused to submit to formal intelligence tests. The examiner however was able to conclude from her alert attitude and intelligent conversation that she showed no evidence of the cerebral disease which afflicted her twin.

She was interviewed 10 years later (July, 1953) by the same examiner (E. A. D.) who had seen her on that earlier occasion. Chrissie, then aged 73, was an alert and active housewife, who dealt efficiently with the cooking, domestic cleaning, and shopping required in a household consisting of herself and a daughter who went out to business each day. Her physical appearance vividly recalled that of the patient at the age of 63 , allowing for such important differences as her neater style of dress and absence of facial rash. The ease with which she supplied chronological data to amplify the family history showed that she had no memory disorder. She answered all factual questions quickly and relevantly, although she was still somewhat hesitant in speaking about her sister's illness, a hesitancy which was interpreted as indicating some still persisting anxiety on this subject. In neither speech nor action did she give any impression of intellectual deterioration, and her excellent physical and mental health was confirmed not merely by her daughter, but by the more impartial evidence of neighbours and friends.

\section{Necropsy Report}

The body was that of an extraordinarily emaciated elderly woman with sacral bedsores. Permission was granted to examine only the brain, which showed gross generalized atrophy.

Brain after Fixation. - The leptomeninges had a cloudy opalescent appearance. The basal vessels showed patchy atheroma. Marked gyral atrophy with widening of the sulci was apparent over both cerebral hemispheres, the atrophy being particularly severe in both frontal lobes and adjoining anterior parts of both parietal lobes. A serial coronal section of the cerebrum revealed distinct atrophy of both grey and white matter with compensatory dilatation of the ventricles.
Histology.-Sections were examined from the frontal, parietal, and occipital lobes, cornu Ammonis, basal ganglia, and midbrain. Chromatin stains and metallic impregnation methods were used. The small meningeal and cerebral vessels revealed no pathological change. All parts of the cortex showed widespread loss of nerve cells from all layers, while many surviving cells were shrunken and atrophic, often showing senile lipochrome pigmentation. There was a considerable proliferation of coarse fibrillary astrocytes in all parts of the grey matter. In addition, numerous well formed argyrophile plaques were present throughout the cortex, while some of the surviving nerve cells showed thickening of their intracellular neurofibrils, producing Alzheimer's neurofibrillary tangles, although this last feature was not quite so marked here as in many cases of Alzheimer's disease.

\section{Discussion}

If the twins are accepted as being monozygotic, environmental aetiological factors may be said to be proved in this instance of Alzheimer's disease, the significant factors being obscured by the multiple deviations found in comparing the two life histories. Of the divergent aspects of the histories, special mention may be made of the febrile delirium from? which the affected twin suffered during the 1918-19응 influenza epidemic, since this illness may have been encephalitis. Greenfield and Bosanquet (1953) have@ found neurofibrillary tangles similar to those found in Alzheimer's disease in the pigmented cells of the brain-stem in post-encephalitic Parkinsonism, andog quote other authors who have described similar changes in the cortical nerve cells in cases of subacute inclusion and subacute sclerosing encephalitis. Also of possible significance is the 20 years' residence of the unaffected twin in Australia, with its different climatic and dietary conditions and its relative freedom from dietary restriction during the 1914-18 war.

Genetic aetiological factors in Alzheimer's disease, demonstrated by various authors, can be neither proved nor disproved in our case. Patterns of inheritance strongly suggestive of the transmission of a recessive gene are found in the pedigrees of Alzheimer's disease described by Lowenberg and Waggoner (1934) and by McMenemey, WorsterDrought, Flind, and Williams (1939). Those first affected were the children of first-cousin marriages : the appearance of the character in the subsequent generation in each pedigree can be explained only by the mating of a homozygous affected with a heterozygous normal, a circumstance indicative of a relatively high rate of heterozygous normals in the population. The family histories of cases described by Schottky (1932), Grünthal and Wenger (1939), van Bogaert, Maere, and de Smedt (1940), who described two cases, and Essen-Möller (1946) all 
admit of transmission of an autosomal or partially sex-linked dominant gene, there being in each instance a "vertical " distribution of affected persons, of whom all had one affected parent so far as could be traced.

From the available evidence, we must either ascribe to this clinico-pathological entity alternative aetiological factors of such diversity as heredity and environment or agree with McMenemey (1940) that " both endogenous and exogenous factors may be involved in any given case with pathology of the Alzheimer type ". It may be that, in the ostensibly hereditary cases, environmental factors determine the timing and degree of expression of genetic factors.

An interesting feature of this case was the acne rosacea which appeared simultaneously with the mental symptoms and was never present in the healthy twin. Lewis (1934) has reported discordance for acne rosacea and acromegaly in uniovular twins, whereas Hutchinson (1891) and Lesser (quoted by Siemens, 1926) describe hereditary cases of rosacea. The discordance of monozygotic twins for two genetic characters would favour the possibility of somatic mutation having occurred in one twin. In such a circumstance a gene with pleiotropic effects must be envisaged or disturbance of the gene company by mutation allowing for the expression of a linked gene. Such mutation occurring in one of identical genotypes must be determined by environmental factors.

We have recently observed the association of Alzheimer's disease with rosacea in a second case. A third case of Alzheimer's disease, an emaciated patient, showed widespread bu lous eruptions and skin atrophy which, together with the cerebral lesion, were confirmed at necropsy. These cases are of interest, since Schottky (1932) believed that hereditary impairment of the primitive ectoderm was probably a factor in Alzheimer's disease. The validity of this theory could be tested by clinical scrutiny of the ectodermal structures and skin biopsy in early cases.

\section{Summary}

Monozygotic twins discordant for Alzheimer's disease and acne rosacea are described. Neuropathological findings in the affected twin are reported.

Environmental factors are, of necessity, postulated to account for the discordance.

The significance of the findings is discussed in relation to aetiological factors in Alzheimer's disease.

We wish to express our thanks to Professor Sir David K. Henderson for permission to publish this case and to Professor F. A. E. Crew for his advice on the genetic aspects. We are indebted to Dr. W. M. McAlister for pərmission to study skin biopsies at Bangour Mental Hospital and to Dr. N. Maclean for the histological report on a section of skin. Miss R. Morrison, psychiatric social worker, gave invaluable assistance in tracing the family history.

The neuropathological examination of this case of Alzheimer's disease was carried out by the late Dr. William Forbes.

\section{REFERENCES}

Alzheimer, A. (1907). Allg. Z. Psychiat., 64, 146

Bogaert, L. van, Maere, M., and de Smedt, E. (1940). Mschr. Psychiat. Neurol., 102, 249.

Critchley, M. (1933). Proc. roy. Soc. Med., 26, 1077.

Essen-Möller, E. (1946). Acta psychiat., Kbhh., 21, 232.

Greenfield, J. G., and Bosanquet, F. D. (1953). Journal of Neurology. Neurosurgery and Psychiatry, 16, 213.

Grünthal, E., and Wenger, O. (1939). Mschr. Psychiat. Neurol., 101,8 .

Hutchinson, J. (1891). Brit. J. Dermat., 3, 1.

Kraepelin, E. (1910). Psychiatrie, vol. 2, p. 624. Barth, Leipzig.

Lewis, A. J. (1934). J. Neurol. Psychopath., 15, 1.

Lowenberg, K., and Waggoner, R. W. (1934). Arch. Neurol. Psychiat., Chicago, 31, 737.

McMenemey, W. H. (1940). J. Neurol. Psychiat., 3, 211. Worster-Drought, C., Flind, J., and Williams, H. G. (1939). Ibid., 2, 293

Newton, R. D. (1948). J. ment. Sci., 94, 225.

Newton, R. D. (1948). J. ment. Sci., 94, 225.

Siemens, H. W. (1926). Münch. med. Wschr., 73, 1514.

Sjögren, T., Sjögren, H., and Lindgren, §. G. H. (1952). Acta Psychiat., Kbh., Suppl. 82.

Slater, E. (1950). In Recent Progress in Psychiatry, ed. G. W. T. H. Fleming, vol. 2., p. 18. (J. ment. Sci., special issue.) J. and A. Churchill, London.

In the paper on "The Effect of Temporal Lobectomy upon Two Cases of an Unusual Form of Mental Deficiency", by D. W. Liddell and D. W. C. Northfield, in the November, 1954, issue, the E.E.G. in Fig. 6, page 270, should be transposed with that in Fig. 7, page 272. 